\title{
The permeation of dynorphin A 1-6 across the blood brain barrier and its effect on bovine brain microvessel endothelial cell monolayer permeability
}

\author{
Courtney D. Kuhnline Sloan ${ }^{\mathrm{a}, \mathrm{d}}$, Kenneth L. Audus ${ }^{\mathrm{a}}$, Jane V. Aldrich ${ }^{\mathrm{b}, \mathrm{d}}$, and Susan M. \\ Lunte ${ }^{\mathrm{a}, \mathrm{c}, \mathrm{d},{ }^{*}}$ \\ aDepartment of Pharmaceutical Chemistry, University of Kansas, Lawrence, KS, USA \\ bDepartment of Medicinal Chemistry, University of Kansas, Lawrence, KS, USA \\ 'Department of Chemistry, University of Kansas, Lawrence, KS, USA \\ ${ }^{\mathrm{d}}$ Ralph N. Adams Institute for Bioanalytical Chemistry, University of Kansas, Lawrence, KS, USA
}

\section{Abstract}

Dynorphin A 1-17 (Dyn A 1-17) is an endogenous neuropeptide known to act at the kappa opioid receptor; it has been implicated in a number of neurological disorders, including neuropathic pain, stress, depression, and Alzheimer's and Parkinson's diseases. The investigation of Dyn A 1-17 metabolism at the blood-brain barrier (BBB) is important since the metabolites exhibit unique biological functions compared to the parent compound. In this work, Dyn A 1-6 is identified as a metabolite of Dyn A 1-17 in the presence of bovine brain microvessel endhothelial cells (BBMECs), using LC-MS/MS. The transport of Dyn A 1-6 at the BBB was examined using this in vitro cell culture model of the BBB. Furthermore, the permeation of the BBB by the low molecular weight, permeability marker fluorescein was characterized in the presence and absences of Dyn A 1-6.

\section{Introduction}

\begin{abstract}
Investigating the transport and metabolism of endogenous substances at the blood brain barrier (BBB) is important for determining their potential role in neurodegenerative diseases. In particular, the metabolism and transport of neuropeptides at the BBB can provide insight into their role in CNS disorders. Dynorphin A 1-17 (Dyn A 1-17) is an endogenous neuropeptide known to act at the kappa opioid receptor. Upregulation of Dyn A 1-17 synthesis has been implicated in a variety of neurological disorders, including Alzheimer's [20], Parkinson's [11], neuropathic pain [14], stress[12], and depression [17], and at elevated concentrations, has been shown to be neurotoxic $[9,10,15]$. Once released into the extracellular space, neuropeptides undergo enzymatic degradation, and therefore, investigating Dyn A 1-17 metabolism at the blood-brain barrier (BBB) is important since the metabolites exhibit unique biological functions compared to the parent compound.
\end{abstract}

\footnotetext{
(C) 2012 Elsevier Inc. All rights reserved.

"Correspondence: Dr. Susan M. Lunte, Ralph N. Adams Institute for Bioanalytical Chemistry, University of Kansas, 2030 Becker Drive, Lawrence, KS 66045, USA, slunte@ku.edu, Telephone: +1-785-864-3811, Fax: +1-785-864-1916.

Publisher's Disclaimer: This is a PDF file of an unedited manuscript that has been accepted for publication. As a service to our customers we are providing this early version of the manuscript. The manuscript will undergo copyediting, typesetting, and review of the resulting proof before it is published in its final citable form. Please note that during the production process errors may be discovered which could affect the content, and all legal disclaimers that apply to the journal pertain.
} 
Therefore, it is possible that a metabolite, rather than the parent peptide, may be responsible for some of the reported neurotoxic effects of dynorphin.

Dyn A 1-6, the N-terminal fragment of Dyn A 1-17, has been identified as a major metabolite of the parent peptide Dyn A 1-17, by our group and others, in both the central nervous system (brain and spinal cord) $[11,13,16]$ and peripheral tissues (blood and plasma) $[6,7,13,21]$. Therefore, this communication describes the initial studies employed to characterize the BBB permeability of Dyn A 1-6 and the effect of the peptide on cell monolayer integrity, utilizing the in vitro cell culture model of the BBB developed by Audus and Borchardt [1]. The bovine brain microvessel endothelial cells (BBMECs) [1] cells exhibit many of the physical characteristics typical of the BBB such as tight junctions, decreased pinocytosis, and minimal fenestration. Additionally, the biological aspects of the blood-brain barrier are simplified considerably enabling the investigation of a compound's behavior at the brain endothelium as opposed to the whole brain [8].

The studies described here employed liquid chromatography with tandem mass spectrometry (LC-MS/MS) to determine the permeation of Dyn A 1-6 across the BBMEC monolayers. The LC-MS/MS method required minimal sample preparation and no derivatization steps. Improved limits of detection were achieved using LC-MS/MS in comparison to a previously described CE-UV method [13]. Additionally fluorescein was employed as a low molecular weight, membrane-impermeant molecule to probe the effect of Dyn A 1-6 on cell monolayer integrity. This is the first report examining the transport of Dyn A 1-6 using BBMECs.

\section{Experimental}

\subsection{Materials}

All dynorphin peptides (Dyn A 1-17, 2-17, 1-13, 1-8, and 1-6) were obtained from Bachem Biosciences Inc. (King of Prussia, PA, USA). Bradykinin was purchased from Sigma-Aldrich (St. Louis, MO, USA). Fisher Optima acetonitrile (LC-MS grade) was used for all mobile phases (Fisher Scientific, Fair Lawn, NJ, USA). Formic acid was purchased from Acros Organics (Morris Plains, NJ, USA) at 99.9\% purity. All aqueous mobile phases were made from $18 \mathrm{M} \Omega$ deionized (D.I.) water from a benchtop Milli-Q Synthesis A10 Water Purification System (Millipore, Billerica, MS, USA) and filtered with $0.2 \mu \mathrm{m}$ Magna nylon filters from Osmonics (Minnetonka, MN, USA). Minimum essential medium (MEM) and Ham's F12 were purchased from Life Technologies, Invitrogen Corporation (Carlsbad, CA, USA). All other reagents were purchased from Sigma Aldrich.

\subsection{Isolation and maintenance of bovine brain microvessel endothelial primary cultures}

Microvessel endothelial cells were isolated from the cortical grey matter of bovine brains by enzymatic digestion and centrifugation as described by Audus and Borchardt in 1986 [1]. A short description of the isolation procedure is included in the Supplemental Information.

\subsection{Analysis of BBMEC integrity and Dyn A 1-6 transport at the cell monolayer}

At the beginning of each transport study, the polycarbonate membranes were removed and mounted in Side-by-Side ${ }^{\mathrm{TM}}$ diffusion chambers (Crown Glass Inc., Somerville, NJ, USA). Prior to studies, the diffusion chambers were silanized with Sigmacote (Sigma-Aldrich) to prevent peptide adsorption to the chamber walls during the study. On the day of the study, chambers were pre-warmed $\left(37^{\circ} \mathrm{C}\right)$ and rinsed three times with mPBSA. The chamber temperature was maintained for the duration of the study by external circulating water baths (at either $37{ }^{\circ} \mathrm{C}$ or $4{ }^{\circ} \mathrm{C}$, depending on the experiment) and each chamber was stirred constantly at $600 \mathrm{rpm}$ by Teflon-coated magnetic stir bars driven by an external console. 
The donor side was then spiked with Dyn A 1-6, and $60 \mu \mathrm{L}$ aliquots were removed from the receiver side at various timepoints and replaced with an equal volume of mPBSA to prevent changes in volume that could affect flux. Studies typically lasted $2-4 \mathrm{~h}$. All samples were collected into autosampler vials containing $\mathrm{H}_{2} \mathrm{O}$ with formic acid. Mass balance samples were collected from the receiver chamber at the start and finish of each experiment. Quantitation was performed via LC-MS/MS. All Liquid chromatography-tandem mass spectrometry instrumentation and experimental details are described in the supplemental information.

Upon completion of the transport study, fluorescein was added to the apical side of the monolayer and utilized to test the monolayer integrity. Immediately, a $100 \mu \mathrm{L}$ aliquot was removed from the donor chamber and placed in a 96-well plate. Additional $100 \mu \mathrm{L}$ aliquots were taken from the receiver chamber $(\mathrm{t}=10,20,30$, and $60 \mathrm{~min})$, and a final sample was taken from the donor chamber after $60 \mathrm{~min}$ as well. Fluorescein samples were placed directly into a 96-well plate and analyzed using a fluorescence microplate spectrophotometer (Molecular Devices, Sunnydale, CA, USA) at excitation and emission wavelengths of 490 and $520 \mathrm{~nm}$, respectively.

For studies determining the permeation of fluorescein without Dyn A 1-6 pretreatment, chambers were filled with the modified medium (mPBSA), and the cells were allowed to equilibrate for $5 \mathrm{~min}$. After the equilibration period, fluorescein was added to the apical side and samples were removed from the donor chamber as described above.

All permeation values determined using the following equation: $\mathrm{P}_{\text {app }}=(\Delta \mathrm{Q} / \Delta \mathrm{t}) / \mathrm{A} \times \mathrm{C}_{0}$, where $\Delta \mathrm{Q} / \Delta \mathrm{t}$ is the linear appearance of fluorescein in the receiver chamber, $\mathrm{A}$ is the crosssectional area of the cell monolayer $\left(0.636 \mathrm{~cm}^{2}\right)$, and $\mathrm{C}_{0}$ is the initial concentration in the donor chamber at $\mathrm{t}=0$.

\section{Results}

In this work and that of others, Dyn A 1-6 has been identified as a major metabolite of the parent peptide Dyn A 1-17 in both the central nervous system (brain and spinal cord) [11, $13,16]$ and peripheral tissues (blood and plasma) [6, 7, 13, 21]. Dyn A 1-6 was also identified as a metabolite in the presence of bovine brain microvessel endothelial cells (BBMEC) (supplemental information- Figure S1). For this reason, the BBB permeability of Dyn A 1-6 was investigated, using BBMECs grown on polycarbonate membranes and mounted in Side-by-Side ${ }^{\mathrm{TM}}$ diffusion chambers. Fluorescein was utilized as a low permeability control following all experiments to examine monolayer integrity.

Both the directional and temperature dependence of Dyn A 1-6 permeation were determined by replacing $20 \mu \mathrm{L}$ of mPBSA with Dyn A 1-6 stock solution resulting in a peptide concentration of $18.6 \mu \mathrm{M}$ in the donor compartment. The apparent permeability coefficient of Dyn A 1-6 was calculated to be $\mathrm{P}_{\text {app }}=6.59 \times 10^{-5} \mathrm{~cm} / \mathrm{s}\left( \pm 1.74 \times 10^{-5} \mathrm{n}=4\right)$, in the apical to basolateral direction, and $\mathrm{P}_{\mathrm{app}}=6.43 \times 10^{-5} \mathrm{~cm} / \mathrm{s}\left( \pm 1.61 \times 10^{-5} \mathrm{n}=4\right)$, in the basolateral to apical direction. There was no difference in the permeability based on direction (Fig. 1A). A decrease in permeation was observed at $4{ }^{\circ} \mathrm{C}, \mathrm{P}_{\mathrm{app}}=1.11 \times 10^{-5} \mathrm{~cm} / \mathrm{s}$ $\left( \pm 2.90 \times 10^{-6}, n=4, p<0.005\right)$, suggestive of a carrier-mediated transport system (Fig. 1A). Fluorescein was utilized as a low molecular weight permeability marker and control following the end of each experiment. Values for fluorescein permeation are presented in Fig. 1B.

Interestingly the permeation values for fluorescein were increased following Dyn A 1-6 exposure at $37{ }^{\circ} \mathrm{C}$ in comparison to those at $4{ }^{\circ} \mathrm{C}$. Thus control experiments were performed to confirm the permeation value for fluorescein without Dyn A 1-6 preincubation. 
Fluorescein permeation was calculated to be $3.42 \times 10^{-5} \mathrm{~cm} / \mathrm{s}\left( \pm 2.90 \times 10^{-5} \mathrm{n}=4\right)$, and this value agrees well with previous literature reports $[18,19]$, indicating that the cell monolayers were confluent and intact on the polycarbonate membranes.

The effect of Dyn A 1-6 preincubation on fluorescein permeation was further investigated by incubating mounted monolayers for $2 \mathrm{~h}$ in mPBSA at $37^{\circ} \mathrm{C}$. Following the 2-h incubation, 0,20 , and $100 \mu \mathrm{L}$ of mPBSA were removed and replaced with Dyn A 1-6 resulting in final concentrations in the chamber of $0,18.6$, and $46.6 \mu \mathrm{M}$. The fluorescein permeability increased in a linear fashion with increasing exposure to Dyn A $1-6, \mathrm{R}^{2}=$ 0.9995. The permeation values for Dyn A 1-6 in the apical-to-basolateral and basolateral-toapical directions fall along this line, as shown by the open square and open diamond data points in Fig. 2, suggesting that this peptide is responsible for increasing BBB permeability. A similar phenomenon was observed by Thompson and Audus with the opioid peptide leucine enkephalin $[18,19]$, and the reported values for fluorescein permeation both with and without leucine enkephalin pretreatment are also plotted in Fig. 2 for comparison.

\section{Discussion}

It has been reported that leucine enkephalin can increase the permeation of low molecular weight, membrane-impermeant molecules such as sucrose and fluorescein in a concentration-, energy-, and temperature-dependent manner [2, 18, 19]. Metabolites of Leuenkephalin did not exhibit this effect, nor did metabolically stable analogs. It is also well known that there exists a saturable peptide transport system for small, N-tyrosinated peptides at the blood-brain barrier [3-5], and that this system is responsible for the brain-toblood efflux of the small opioid peptide leucine enkephalin. Thompson and Audus found that non-opioid peptides capable of utilizing this transport system did not alter BBB permeability to fluorescein or sucrose, suggesting that binding this efflux system is not responsible for BBB opening $[18,19]$. However, the use of naloxone, a mu- and delta-opioid antagonist, was shown to attenuate the increased transport caused by Leu-enkephalin.

This result indicates that opioid receptor activity (delta or mu) may play a role in the ability of these peptides to open the BBB. Dyn A 1-17 acts preferentially at the kappa-opioid receptor, while Dyn A 1-6 shares affinity for the kappa, mu, and delta receptors. Dyn A 1-6 has not been found to be neurotoxic, but it could be responsible for opening the blood-brain barrier, allowing increased transport of the parent peptide in addition to other harmful substances. Further studies are underway to determine the mechanism responsible for the Dyn A 1-6-induced increase in BBB permeability.

\section{Conclusions}

This paper describes the application of the BBMEC culture model to the permeation of Dyn A 1-6, a metabolite of the neuropeptide Dyn A 1-17, at the blood brain barrier. LC-MS/MS was utilized to quantify Dyn A 1-6 in order to determine the bi-directional permeation of the peptide the BBB. Dyn A 1-6 transport was decreased at $4{ }^{\circ} \mathrm{C}$, indicating an energy- (ATP) driven transport mechanism is likely responsible. The metabolite was also found to increase the permeability of the BBB to a low molecular weight, low permeability control substance, fluorescein. Such effects suggest a role of this dynorphin metabolite in the opening of the $\mathrm{BBB}$, specifically to low molecular weight compounds, including the peptide itself.

\section{Supplementary Material}

Refer to Web version on PubMed Central for supplementary material. 


\section{Acknowledgments}

The authors gratefully acknowledge Giuseppe Caruso and Dulan Gunasekara for their help in the isolation and maintenance of BBMEC cultures. Funding for this project was provided by National Institutes of Health Grants NINDS R56-NS042929 and NIDA R01 DA0239244. CDKS acknowledges the support of a predoctoral fellowship from Pfizer. We also would like to thank Nancy Harmony for editorial support.

\section{References}

1. Audus KL, Borchardt RT. Characterization of an in vitro blood-brain barrier model system for studying drug transport and metabolism. Pharm Res. 1986; 3:81-87.

2. Baba M, Oishi R, Saeki K. Enhancement of blood-brain permeability to sodium fluorescein by stimulation of $\mu$-opioid receptors in mice. Naunyn-Schmiedeberg's Arch Pharmacol. 1988; 337:423-428. 337. [PubMed: 2841613]

3. Banks WA, Kastin AJ, Fishman AJ, Coy DH, Strauss SL. Carrier-mediate transport of enkephalins and n-tyr-mif-1 across the blood-brain barrier. Am J Physiol. 1986; 251:E477-E482. [PubMed: 2876644]

4. Banks WA, Kastin AJ, Michals EA. Tyr-mif-1 and met-enkephalin share a saturable blood-brain barrier transport system. Peptides. 1987; 8:899-903. [PubMed: 2893362]

5. Banks WA, Kastin AJ, Nager BJ. Transport system for tyr-mif-1/enkephalins: Evidence for a dissociation. Neuropharmacology. 1988; 27:174-179.

6. Chou JZ, Chait BT, Wang R, Kreek MJ. Differential transformation of dynorphin a (1-17) and dynorphin a (1-13) peptides in human blood, ex vivo. Peptides. 1996; 17:983-990. [PubMed: 8899817]

7. Chou JZ, Kreek MJ, Chait BT. Matrix-assisted laser desorption mass spectrometry of biotransormation products of dynorphin a in vitro. J Am Soc Mass Spectrom. 1994; 5:10-16.

8. Gumbleton M, Audus KL. Progress and limitations in the use of in vitro cell cultures to serve as a permeability screen for the blood-brain barrier. J Pharm Sci. 2001; 90:1681-1698. [PubMed: 11745727]

9. Hauser KF, Aldrich JV, Anderson KJ, Bakalkin G, Christie MJ, Hall ED, et al. Pathobiology of dynorphins in trauma and disease. Front Biosci. 2005; 10:216-235. [PubMed: 15574363]

10. Hauser KF, Knapp PE, Turbek CS. Structure-activity analysis of dynorphin a toxicity in spinal cord neruons: Intrinsic neurotoxicity of dynorphin a and its carboxyl-terminal, nonopioid metabolites. Exp Neurol. 2001; 168:78-87. [PubMed: 11170722]

11. Klintenberg R, Andren PE. Altered extracellular striatal in vivo biotransformation of the opioid neuropeptide dynorphin a (1-17) in the unilateral 6-ohda rat model of parkinson's disease. J Mass Spectrom. 2005; 40:261-270. [PubMed: 15706626]

12. Knoll AT, Carlezon WA Jr. Dynorphin, stress, and depression. Brain Res. 2010; 1314:56-73. [PubMed: 19782055]

13. Kuhnline CD, Lunte SM. Evaluation of an on-capillary copper complexation methodology for the investigation of in vitro metabolism of dynorphin a 1-17. J Sep Sci. 2010; 33:2506-2514. [PubMed: 20658491]

14. Lai J, Ossipov MH, Vanderah TW, Malan J, T P, Porreca F. Neuropathic pain:The paradox of dynorphin. Mol Interventions. 2001; 1:160-167.

15. Nardo L, Soong Y, Wu D, Young IR, Walker D, Szeto HH. Site and mechanism of action of dynorphin a-(1-13) and n-methyl-d-aspartate on acth release in fetal sheep. Am J Physiol Endocrinol Metabol. 2002; 282:1301-1307.

16. Reed B, Zhang Y, Chait BT, Kreek MJ. Dynorphin a (1-17) biotransformation in striatum of freely moving rats using microdialysis and matrix-assisted laser desorption/ionizationmass spectrometry. J Neurochem. 2003; 86:815-823. [PubMed: 12887680]

17. Shirayama Y, Ishida H, Iwata M, Hazama G, Kawahara R, Duman RS. Stress increases dynorphin immunoreactivity in limbi brain regions and dynorphin antagonism produces antidepressent-like effects. J Neurochem. 2004; 90:1258-1268. [PubMed: 15312181]

18. Thompson SE, Audus KL. Leucine enkephalin effects on brain microvessel endothelial cell monolayer permability. Pharm Res. 1994; 11:1366-1369. [PubMed: 7816772] 
19. Thompson SE, Cavitt J, Audus KL. Leucine enkephalin effects on paracellular and transcellular permeation pathways across brain microvessel endothelial cell monolayers. J Cardiovasc Pharmacol. 1994; 24:818-825. [PubMed: 7532761]

20. Yakovleva T, Marinova Z, Kuzmin A, Seidah NG, Haroutunian V, Terenius L, et al. Dysregulation of dynorphins in alzheimer disease. Neurobiol Aging. 2006; 14:1700-1708. [PubMed: 16914231]

21. Yu J, Butelman ER, Woods JH, Chait BT, Kreek MJ. In vitro biotransformation of dynoprhin a (117 ) is similar in human and rhesus monkey blood as studied by matrix-assisted laser desorption/ ionization mass spectrometry. J Pharmacol Exp Ther. 1996; 279:507-514. [PubMed: 8930152] 


\section{Highlights}

- Dynorphin A 1-6 is identified as a metabolite of Dynorphin A 1-17 in the presence of bovine brain microvessel endothelial cells (BBMECs).

- The blood brain barrier (BBB) permeability of the neuropeptide Dyn A 1-6 is investigated using the BBMEC culture model of the BBB.

- The directional and temperature dependent permeation of Dyn A 1-6 is evaluated.

- Dyn A 1-6 pretreatment is found to induce an opening of the BBB, increasing the permeation of fluorescein, a low molecular weight, low permeability control substance. 
A

Apparent Permeation of Dyn A 1-6

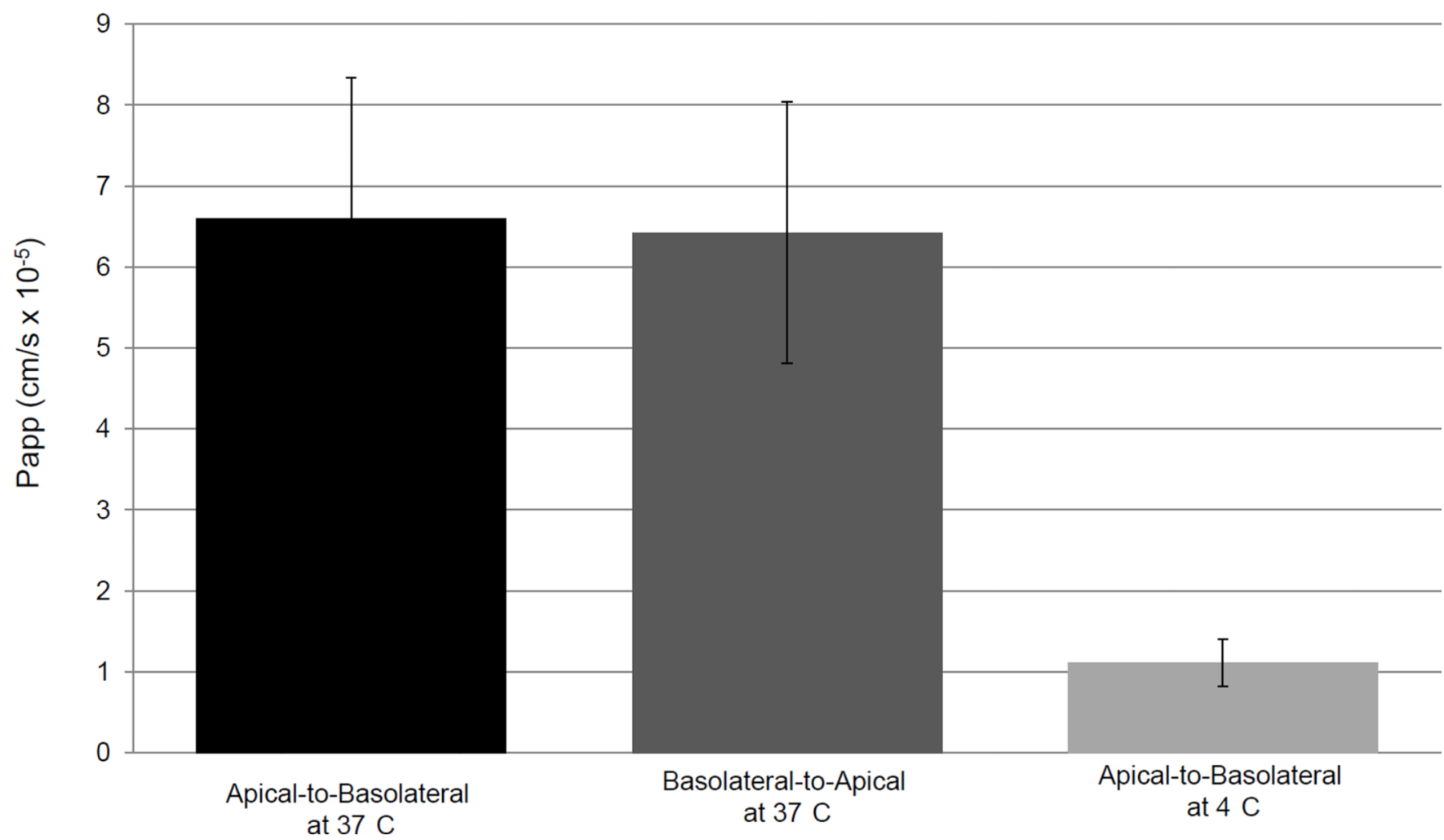


B

\section{Effect of Dyn a 1-6 on Fluorescein Permeation}

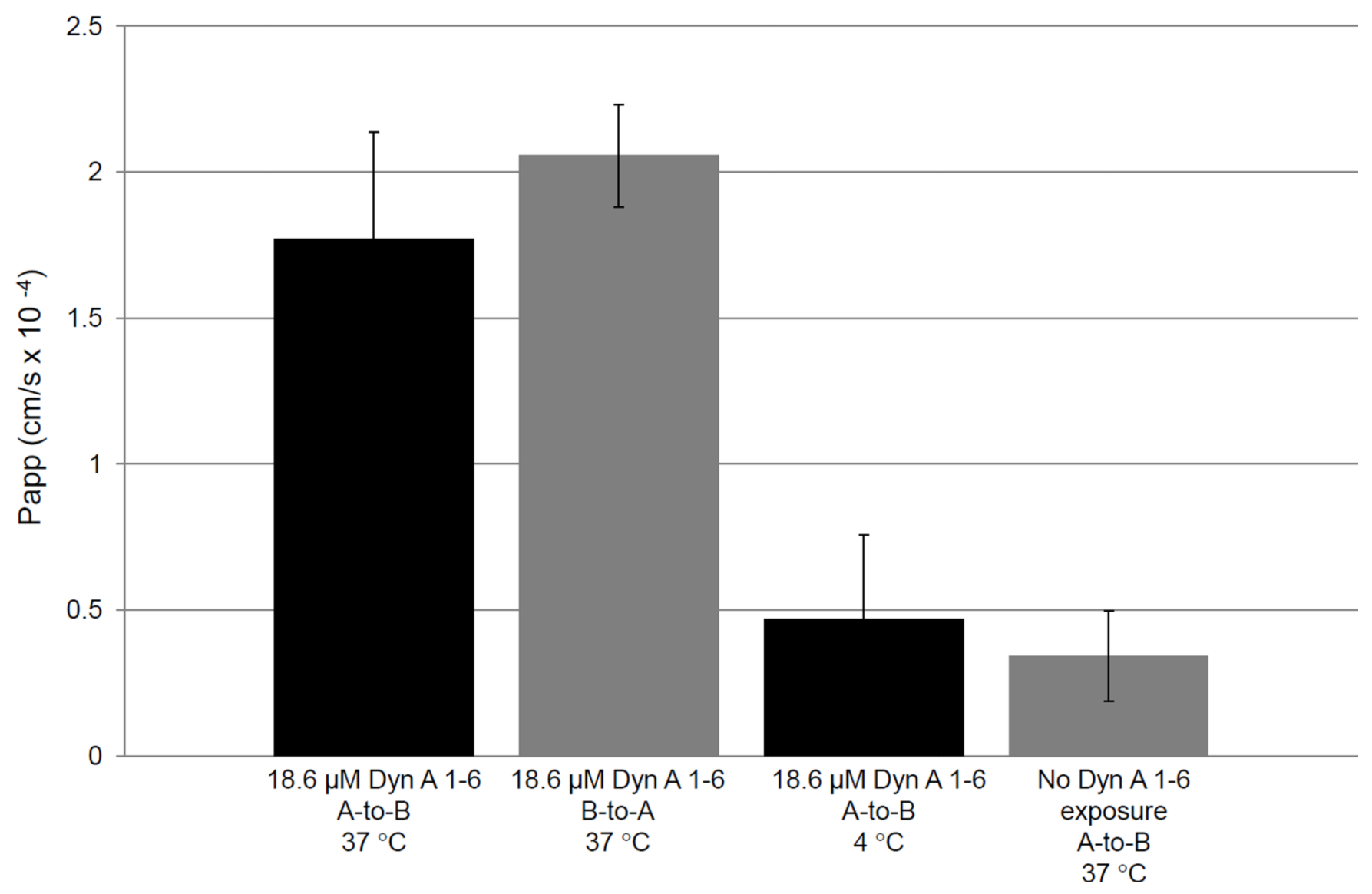

Fig. 1.

(A) Bi-directional apparent permeability coefficients of Dyn A 1-6 ( $\mathrm{n}=4$ in each direction) and the temperature dependence of the apical-to-basolateral transport of Dyn A $1-6(n=4$ at each temperature) $\mathrm{p}<0.005$. (B) Effect of pretreatment with $18.6 \mu \mathrm{M}$ Dyn A $1-6$ on the BBB permeability of the low molecular weight, low permeation marker, fluorescein (10 $\mu \mathrm{M}), \mathrm{n}=4$. 


\section{Effects of Dyn A 1-6 on $P_{\text {app }}$ of Fluorescein}

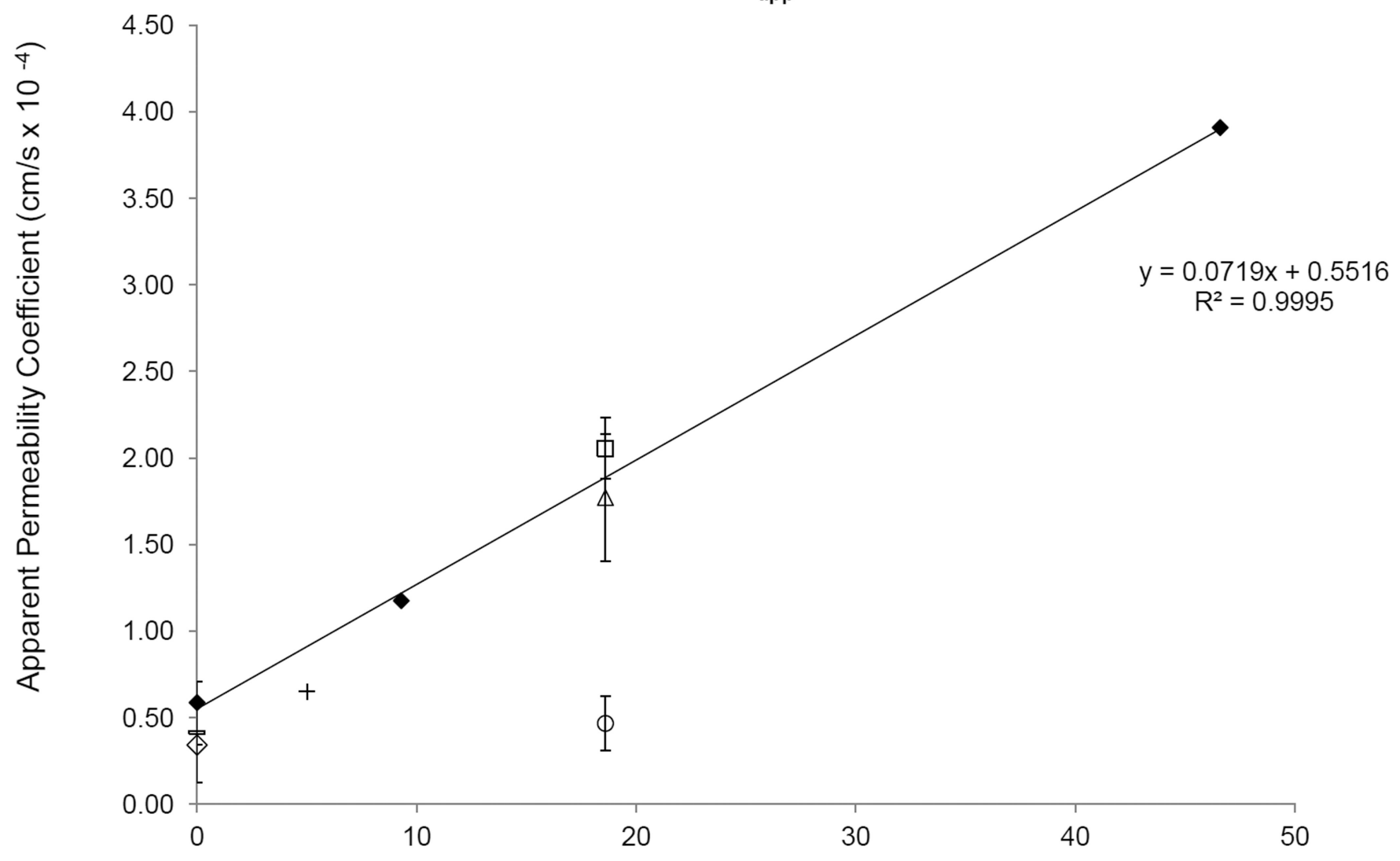

\section{Dyn A 1-6 Concentration ( $\mu \mathrm{M})$}

Fig. 2.

Effect of pretreatment with varying Dyn A 1-6 concentrations (solid diamonds) on the BBB permeation of the low molecular weight, low permeability marker fluorescein $(10 \mu \mathrm{M})$.

Fluorescein permeation without Dyn A 1-6 incubation (open diamonds), fluorescein permeation following 240-min Dyn A 1-6 pretreatment A to B (open triangles) and B to A (open squares), and fluorescein permeation following 120-min Dyn A 1-6 pretreatment at 4 ${ }^{\circ} \mathrm{C}$ (open circles). Also shown are literature values for the permeation of fluorescein alone (dash) and following pretreatment with leucine enkephalin (plus sign). 